\title{
FACP Regimen
}

National Cancer Institute

\section{Source}

National Cancer Institute. FACP Regimen. NCI Thesaurus. Code C9539.

A chemotherapy regimen consisting of fluorouracil, doxorubicin, cyclophosphamide, and cisplatin that may be used in the treatment of salivary gland carcinoma. 